\title{
El «neutro de materia» en los Libros de los Expósitos del Real Hospicio de Uviéu (s. XVIII)*
}

\author{
The neutro de materia in the Libros de los Expósitos of the \\ Uviéu's Royal Hospice (18 ${ }^{\text {th }}$ century) \\ Claudia Elena Menéndez Fernández \\ Universidá d'Uviéu / Universidad de Oviedo
}

Resumen. En este trabajo se pretende contribuir al estudio del neutro de materia en la lengua asturiana desde una perspectiva diacrónica, a partir del análisis de una serie de ejemplos extraídos de los Libros de los Expósitos del Real Hospicio de Uviéu. Estos libros, escritos en castellano aunque con numerosas interferencias del asturiano, registran la información relativa a cada niño que se abandonaba en la institución y proporcionan un gran número de casos en que se expresa la diferencia semántica entre la continuidad y la discontinuidad del sustantivo mediante la concordancia de «neutro». Se realiza un estudio morfosintáctico de los ejemplos comprendidos entre los años 1752 y 1799 que muestra una preferencia de uso de este tipo de concordancia con adjetivos en función nominal.

Palabras clave: neutro de materia, expósitos, Hospicio, asturiano, morfología diacrónica

Data de recepción: 03-01-2019 - Data de aceptación: 26-07-2019.

* Este trabajo se ha realizado bajo el amparo de una ayuda predoctoral del Programa «Severo Ochoa» para la formación en investigación y docencia (BP17-79) financiada por la Consejería de Educación y Cultura del Principado de Asturias.

El artículo que aquí se desarrolla está basado en una comunicación que se presentó en el XXXIII Congreso Internacional de la Asociación de Jóvenes Lingüistas, celebrado en Ciudad Real (Facultad de Letras, UCLM) los días 17, 18 y 19 de octubre de 2018. 
Abstract. The aim of this paper is to contribute to the study of the neutro de materia in Asturian from a diachronic perspective, through the analysis of a series of examples taken from the Libros de los Expósitos 'Foundling Records' from the Royal Hospice of Uviéu. These books were written in Spanish but contain many interferences from Asturian. They record relevant information of each child abandoned at the Hospice and show a great number of examples involving the semantic distinction between the notion of continuity and non-continuity in nouns through «neuter» concordance. The paper carries out a morphosyntactic study of examples from the period from 1752 to 1799, which contain evidence of the preferential use of this kind of concordance with adjectives that modify nouns.

Keywords: mass neuter, foundlings, Hospice, Asturian language, diachronic morphology

\section{INTRODUCCIÓN}

El llamado «neutro de materia» constituye uno de los rasgos morfosintácticos nominales más peculiares y distintivos de la lengua asturiana, aunque no es exclusivo de ella, pues también se manifiesta con cierta sistematicidad en otras lenguas de la Romania, como el romanche y las variedades suditálicas (Lüdtke 2003: 8) ${ }^{1}$.

Desde que Ramón Menéndez Pidal, en 1897, llamara la atención sobre unas particulares concordancias propias del asturiano con determinados sustantivos «de materia cuando van en singular indicando la materia en general y no ninguna parte ni ningún objeto hecho con ella» (Menéndez Pidal 1962: 109-110), como en los sintagmas del tipo «lleche cuayao», se ha venido desarrollando un gran número de estudios $^{2}$ que tratan de explicar, desde distintas perspectivas, sus posibles orígenes, así como su extensión actual y los factores que condicionan su uso.

El objetivo de este trabajo es contribuir al estudio de este fenómeno en asturiano mediante el análisis - fundamentalmente desde el punto de vista morfosintáctico - de los ejemplos de «neutro de materia» que se pueden encontrar en los Libros de los Expósitos del antiguo Real Hospicio de Uviéu, custodiados en el Archivo Histórico de Asturias (AHA). La documentación estudiada abarca desde el año 1752 — fecha de

1 El castellano no es ajeno tampoco a este fenómeno, como demuestran los estudios de carácter fundamentalmente sincrónico de, entre otros, Fernández-Ordóñez (2006, 2007a). Por el contrario, desde una perspectiva diacrónica son bastante escasos los trabajos sobre el neutro de materia en áreas castellanas. Destacamos en este sentido el estudio de Morala Rodríguez (2015), así como el de Gómez Seibane y Vázquez Balonga (2013), quienes aportan una nutrida relación de ejemplos extraídos de documentación notarial de distintas regiones castellanas en los Siglos de Oro.

2 Dentro del ámbito de la dialectología asturiana, debemos el primer acercamiento descriptivo más o menos riguroso acerca del fenómeno del neutro a María Josefa Canellada (1944: 31-32) que, además, fue la primera en referirse a él con el término de «neutro». 
fundación del hospicio uvieín - hasta el año 1799. Se han tenido en cuenta un total de 82 casos de «neutro», que se relacionan en el anexo final, además de otros ejemplos de interpretación más dudosa y que también son objeto de análisis.

Antes de abordar el estudio morfosintáctico propuesto, nos parece pertinente exponer una breve caracterización del «neutro de materia», así como una descripción y contextualización de la documentación con la que se trabaja.

\section{EL «NEUTRO DE MATERIA»Y SU EMPLEO EN ASTURIANO ${ }^{3}$}

La gramaticalización, mediante concordancias explícitas entre determinados sustantivos y sus adjetivos y referentes pronominales, de la diferencia entre la continuidad y la discontinuidad o «neutro de materia» está documentada en asturiano, por lo menos, desde el siglo XIV, como así lo atestiguan, entre otros, los manuscritos del monasterio de San Pelayo de Uviéu: «diez faniegas de bona escanda limpio e pisado, dadorio et tomadorio por la faniega derecha de Oviedo (a.1349)», «hun çelemin de bona escanda amasado» (a.1361), etc. (García Arias 2003: 273). A partir de estos ejemplos ya se pueden extraer algunas de las características más importantes que definen este fenómeno:

- Se trata, en primer lugar, de una oposición semántica — la de la continuidad o no del sustantivo - que adquiere pertinencia morfológica en los adjetivos y referentes pronominales que concuerdan con él. En consecuencia, el adjetivo asturiano contempla tres terminaciones: bonu (discontinuo masculino), bona (discontinuo femenino) y bono («neutro» continuo).

- Los sustantivos que constituyen el núcleo sintagmático han de ser incontables, esto es, con un contenido semántico continuo (xente, agua, lleche, vinu, madera...). Es este rasgo continuo, con independencia del género del sustantivo o de cualquier otro trazo semántico (animado o inanimado, etc.), el que condiciona la aparición de la concordancia neutra en los términos adyacentes: la cacía puerco ('la vajilla sucia'), la xente ta lloco, el vinu bebiólo too, etc. Por su parte, esta oposición de lo continuo/ discontinuo se ha gramaticalizado de forma sistemática en la expresión de tres pares de sustantivos mediante una [-u] (discontinuo) o una [-o] (continuo), recogidos en el asturiano normativo (Alla 2001: 76): fierru (un fierru) / fierro (materia); pelu (un

Por razones evidentes, solo vamos a apuntar aquí los aspectos más generales y característicos, dado que se trata de una breve contextualización del fenómeno. Puede consultarse el artículo realizado por Ramón d'Andrés Díaz (1993) para una mayor profundización y detalle de su complejidad. 
pelu) / pelo (conjunto indeterminado) y filu (un filu) / filo (materia) ${ }^{4}$. No consideramos aquí otro tipo de concordancias neutras con términos principales del sintagma como infinitivos, oraciones sustantivadas, etc. por ser un fenómeno distinto al que nos ocupa $\mathrm{y}$, además, compartido tanto por el asturiano como por el castellano: fumar es malo I fumar ye malo, etc.

- La posición del término adyacente (adjetivos, referentes pronominales...) ha de ser la de la posposición al sustantivo: la madera seco, mientras que la anteposición rige la concordancia con el género masculino o femenino que tenga el sustantivo: esta madera. Si el término «dependiente» forma parte de un núcleo atributivo o predicativo su posición en la oración no resulta relevante: La madera ta seco, Ta seco yá esta madera.

- El morfema con el que se identifica esta concordancia es - $o$ en la mayor parte del dominio que conoce el fenómeno, esto es, el asturiano centro-oriental. De todas formas, es preciso matizar que en la variedad oriental existe una tendencia a emplear - $o$ en los referentes pronominales, demostrativos y algún indefinido frente al uso de - $u$ (tradicionalmente asociado al género masculino) en los adjetivos calificativos: l'agua ta fríu, pero l'agua esto (Andrés Díaz 1993: 49).

Se han propuesto distintas teorías acerca del origen del «neutro de materia». Fue Dámaso Alonso (1958), en un estudio clásico en el que acuña esta etiqueta, el primero en justificar la distinción 'continuo' - 'discontinuo' y su manifestación en la expresión $-o /-u$ a partir de una diferenciación entre los acusativos neutro y masculino, $-\breve{u m} \mathrm{y} *-\bar{u} m$, respectivamente. Desde entonces, se han sucedido otras teorías, como las propuestas por Helmut Lüdtke (2003) o Jesús Neira (1978), que entendieron esta oposición como fruto de la expansión analógica de las formas neutras de los demostrativos y referentes pronominales al paradigma nominal y que vienen a rechazar que

$4 \quad$ Para más información sobre la pertinencia de -u/-o en los sustantivos en la expresión de la continuidad u otros trazos semánticos afines, puede consultarse Viejo Fernández (2003: 260-285) y San Segundo Cachero (2015), entre otros. Autores como Jesús Neira (1978: 268) defendieron la no pertinencia morfológica de este rasgo en el sustantivo, teoría que queda en parte invalidada ante la existencia de pares como fierru/fierro, pelu/pelo, filu/filo u otros en los que esta gramaticalización no es tan sistemática: felechu/felecho, plásticu/plástico, etc. Desde una perspectiva mucho más amplia acerca del origen y caracterización de este vocalismo nominal final ha de considerarse con particular interés el reciente estudio de Viejo Fernández (2018), donde se esboza la existencia de dos modelos morfonológicos nominales en función del tipo de desinencia y la preferencia de marcación de ciertos valores referenciales del sustantivo: mientras que unas variedades expresan lo incontable por medio de una estructura sintáctica innovadora, otras variedades (en especial las localizadas al sur y oeste del río Nalón) parecen optar por la proyección de la especificidad individual del nombre mediante la gramaticalización de la metafonía o inflexión de la vocal tónica del adjetivo, del sustantivo o de ambos. 
la figura de lo continuo en asturiano sea heredera directa del género neutro latino ${ }^{5}$. Precisamente, a Jesús Neira debemos el primer estudio del «neutro de materia» desde una perspectiva morfosintáctica, que sienta las bases sobre la categorización de este morfema «neutro». El hecho de que la marca propia de estas concordancias sea $-o, \mathrm{y}$ de que esta $-O$ se asocie al neutro y, por ende, a las distinciones de género, provocó que algunos estudiosos vincularan estas concordancias con cuestiones relativas al género, como el mismo D. Alonso (1958) o Martínez Álvarez (1967: 78):

Pero si se analiza sincrónicamente la cuestión se ha de reconocer que el género en el adjetivo es una simple repercusión del género que exige el nombre con quien concierta. Por tanto, son los sustantivos los que han conservado entre sus signos morfológicos la triple distinción genérica, aunque en su significante muchas veces confluyan el masculino y el femenino con el neutro.

Las aportaciones posteriores de la dialectología al estudio de este fenómeno contradicen estas afirmaciones desde el momento en que se comprueba, por ejemplo, que el artículo - como morfema que es del sustantivo-, solo expresa o bien el género masculino o el femenino del sustantivo en cuestión: la sidra frio, el fierro machacao ( lo sidra frío, *lo fierro machacao), o que la posición prenuclear del adjetivo restablece la concordancia con el género del sustantivo. En este sentido, resulta mucho más acertada — y así lo tomamos en este trabajo — la hipótesis planteada por Jesús Neira (1978) y continuada por otros autores (Arias Cabal 1999) de considerar el «neutro de materia» como un morfema ajeno a la categoría del género y más cercano a la categoría del número:

El llamado neutro de materia no es un tercer género y no es, por tanto, incompatible, como lo era en latín, con el masculino o femenino. Esto indica, con toda claridad que el «neutro de materia» no está en la categoría de lo que tradicionalmente se ha llamado género (...) El adjetivo de tres terminaciones (buenu-a-o) no es una rara pervivencia del modelo latino (bonus-a-um). La originalidad del bable consiste (...) en haber introducido una distinción morfológica inexistente en latín: la de continuidad/discontinuidad en el sustantivo, con la repercusión consiguiente en el adjetivo o en el referente pronominal. La marca de continuidad en los adjetivos se sobrepone al género, pero no se confunde con él (Neira 1978: 261-262).

5 La percepción de que el sistema nominal asturiano era análogo al del latín, con motivo de la existencia de una terminación - o para expresar lo neutro frente a lo masculino, ya se encuentra en Caveda y Nava (1887: 49), quien en el prólogo a su Colección de poesías en dialecto asturiano, del año 1839, manifestaba la peculiaridad del adjetivo asturiano terminado en $u, a$, o bonu, bona, bono, «como en lengua del Lacio». 
Así, el llamado «neutro de materia» no supone entonces la categorización de un tipo de género junto con el masculino y el femenino, sino un cierto tipo de «número» (el continuo) diferente del singular y del plural que hace referencia a entidades de materia indeterminadas en cuanto al número de unidades componentes.

\section{LOS LIBROS DE LOS EXPÓSITOS DEL REAL HOSPICIO}

A lo largo de la segunda mitad del siglo XVIII, muchas ciudades del Estado español, entre ellas Uviéu, vieron nacer instituciones como las de los hospicios que, a raíz de la nueva concepción ilustrada de la beneficencia y la caridad, debían acoger un gran número de pobres, huérfanos y expósitos, víctimas de la miseria económica de la época, con el objetivo de convertirlos en seres «útiles» para la sociedad (Anes Fernández 2000: 30). El Hospicio uvieín vio la luz en 1752 gracias a los denodados esfuerzos del entonces regente de la Real Audiencia, don Isidoro Gil de Jaz. Entre la documentación que se conserva en el Archivo Histórico de Asturias acerca de la actividad del Hospicio, encontramos centenares de Libros de los Expósitos de los siglos XVIII, XIX y XX que recogen y sistematizan la información relativa a cada niño abandonado. Cada folio de estos libros suele corresponderse con la entrada de un niño expósito en el que se distingue, por un lado, la cadena antroponímica de identificación del individuo en el encabezado del folio y, por otro lado, un cuerpo de texto en el que se ofrecen datos pertinentes como: fecha de abandono y llegada al Hospicio, circunstancias del abandono, transcripciones de las pequeñas cédulas con que a veces eran abandonados estos niños, descripciones de su estado físico y de la ropa que llevan, con qué nodrizas salen a criarse, etc. Estos datos, con especial atención a las descripciones de la ropa con la que llegaban al Hospicio, conforman la base del estudio que se propone. Se han tenido en cuenta los Libros comprendidos entre el año 1752 y 1799 (un total de 23), de entre los que se han seleccionado 82 ejemplos de «neutro» sobre los que realizar el análisis gramatical. También se han extraído otros 24 casos, de interpretación dudosa, a los que se dedicarán unas reflexiones. Cada ejemplo viene introducido por un número, que se corresponde con la enumeración - según el orden cronológico - seguida en el anexo final y se remata con un código entre paréntesis en el que se indica: número de folio del libro, las siglas AHA que indican la procedencia de la documentación (Archivo Histórico de Asturias), la signatura correspondiente a cada libro de expósitos y los años que comprenden. Para facilitar la rápida identificación de los ejemplos del «neutro de materia» se subrayan los sintagmas en los que aparecen dentro de un contexto oracional más amplio. 
La lengua de estos Libros es el castellano, lengua que ocupa los espacios comunicativos formales (y escritos) fruto de la diglosia secular que padece Asturias. De todas formas, este castellano está lleno de interferencias fonético-fonológicas, morfosintácticas y léxicas de la otra lengua ambiental, el asturiano, siendo la del «neutro de materia» la más sistemática y relevante cuantitativamente de todas ellas.

\section{ESTUDIO MORFOSINTÁCTICO}

En cuanto a la metodología de trabajo seguida, optamos por establecer una primera clasificación de los ejemplos de «neutro» en función del tipo de estructura sintagmática en la que aparecen, dado que la posición del término concordado es un factor condicionante de aparición del «neutro» así como su categoría de adyacente o atributo/ predicativo, lo que facilitará la posterior caracterización de los casos propuestos. En este análisis, no vamos a atender al primer nivel sintáctico u oracional (a no ser determinadas excepciones), sino a un segundo nivel de estudio morfosintáctico que se corresponde con el de aquellos sintagmas (nominales y preposicionales fundamentalmente) en los que se integren los distintos ejemplos. Para ello, se manejan tres etiquetas principales: núcleo $(\mathrm{N})$ del sintagma, término adyacente (TAdy) y transpositor (TR). Se presenta, por cada tipo sintagmático estudiado, la relación completa de casos de neutro y los comentarios pertinentes.

\section{Tipo 1: (TAdy) + N + TAdy [TR + N + TAdy $]$}

3 - esta bautizado en la pila del agua bendito de iglesia parroquial y su nombre es Bentura (f-119, AHA-14007, as.1775-1777).

6 - Traia dos fachas ${ }^{6}$ de baeta pagizo, dos escofietas, la una de lienzo pintado... (f-230, AHA14007, as.1775-1777).

8 - Con una papeleta cosida en un liston encarnado con una hebra de seda pagizo, cuya papeleta dezia... (f-91, AHA-14008, as.1777-1778).

15 - Traia una saya de baeta encarnado, almilla y camisa... (f-102, AHA-14010, as.1780-1782).

16 - Embuelto en una mantilla de baeta pagizo, cinta de paño, escofieta y pañuelo en la cabeza. (f-85, AHA-14010, as.1780-1782).

18 - Traia una saya de baeta encarnado, almilla y camisa... (f-102, AHA-14010, as.1780-1782).

6 DALLA: facha, la: sust. Prenda de vistir [pa neños acabante nacer que s'envuelve na cintura y cubre hasta los pies]. 
19 - con una saya de baeta encarnado (f-107, AHA-14010, as.1780-1782).

21 - Embuelto en una facha de mantilla negro y ligado con una faxa blanca de punto (f-330, AHA-14010, as.1780-1782).

22 - Embuelto en dos fachas de baeta pagizo un pañuelo de mosolina aburillado tres pañales y una faxa de punto (f-49, AHA-14011, as.1782-1784).

26 - Embuelta en una mantilla de baeta pagizo con su trenza nueba pastora (f-237, AHA14011, as.1782-1784).

27 - Embuelta en una facha de baeta pagizo y una escofieta atada con una trenza de colores y ligada con una orilla de caldas (f-246, AHA-14011, as.1782-1784).

29 - Embuelta en un pedazo de paño viejo azul unas mangas atadas con una cuerda de lana blanco (f-272, AHA-14011, as.1782-1784).

30 - «Lleva para su abrigo y decencia tres pañales una bara de baeta pagizo y tres baras de cinta pastora con dos paños en la cabeza... (f-274, AHA-14011, as.1782-1784).

31 - Embuelto en unos trapos de sempiterna verde y ligado con unas tiras de baeta negro (f-313, AHA-14011, as.1782-1784).

33 - Embuelta en una facha de lino y lana, 4 pañales y ligada con una tira de baeta negro de cien ilos» (f-230, AHA-14012, as.1784-1786).

35 - Embuelta en dos mantillas de baeta pagizo, gorro de tripe escofieta dos pañales, y una faxa de tienda» (f-86, AHA-14012, as.1784-1786).

38 - Embuelta en un pedazo de manta viejo y unos trapos de camisa por callas ${ }^{7}$, un repuelgo de saya con una cuerda de lana blanco por cinta (f-191, AHA-14012, as.1784-1786).

40 - Embuelta en unos trapos de baeta encarnado, escofieta y cinta de paño (f-125, AHA14013, as.1786-1788).

42 - Embuelto en tres pedazos de mandil, dos pañales y un pañuelo por bastillar con una tercia de sempiterna negro (f-296, AHA-14013, as.1786-1788).

43 - Embuelta en unos trapos de baeta negro y cinta de paño (f-196, AHA-14013, as.1786-1788).

49 - Embuelta en una mantilla y una facha de sarga blanco (f-156, AHA-14014, as.1788-1790).

51 - Embuelto en una facha de baeta encarnado ligado con una cinta angosta de orilla de paño (f-352, AHA-14014, as.1788-1790).

52 - Embuelto en unos pedazos de baeta negro y una cinta baquera con otros trapos (f-22, AHA-14015, as.1790-1791).

DALlA: calla, la: sust. Cacha, pañal [pa neños]. 
54 - Embuelto en una mantilla de baeta pagizo y faxa de punto ancha (f-85, AHA-14015, as.1790-1791).

55 - ...presos con una ebra de seda morado (f-131, AHA-14015, as.1790-1791).

56 - Embuelta en unos trapos de sayal ligada con una cinta de lana negro (f-214, AHA-14015, as.1790-1791).

59 - Embuelta en unos trapos de cobertor ligada con una tira de baeta blanco (f-302, AHA14015, as.1790-1791).

63 - Embuelto en una facha de baeta blanco gorro de lienzo y ligado con un cadarzo de dos generos (f-166, AHA-14017, as.1791-1793).

67 - Embuelto en unos trapos de mediana atados con una cuerda de lana blanco y una tira de camisa con un boton (f-295, AHA-14017, as.1791-1793).

71 - Llamome Nicolasa, nazi al tercero para las doce de oy 5 de Diz de 93, no estoy bautizada llebo dos fachas de vayeta pagizo por hazer... (f-155, AHA-14018, as.1793-1794).

74 - Embuelta en una facha de baeta morado con una tira de terliz (f-92, AHA-14021, as.1796-1797).

75 - Embuelta en unos trapos de saya pagizo cinta de baeton y un gordon de seda (f-104, AHA-14021, as.1796-1797).

80 - Traia vestido una mantilla de vaieta negro, escofieta una faja de pelusa encarnada (f-292, AHA-14021, as.1796-1797).

- La estructura sintagmática de estos ejemplos es la siguiente: un núcleo sustantivo (pedazo, mantilla, etc.) acompañado de un término adyacente antepuesto - excepto en el ejemplo $n^{0} 3$ - que se corresponde con un adjetivo calificativo numeral (una, dos) o indefinido (unos, unas...). Como término adyacente pospuesto al sustantivo núcleo aparece otro sintagma nominal, transpuesto a categoría adjetiva por una preposición (en los ejemplos propuestos, siempre de), y que consta, a su vez, de un sustantivo en función de núcleo y un adjetivo en función de término adyacente que es el que muestra la marca del continuo o «neutro de materia» $(-o)$.

- Los dos condicionantes necesarios para la manifestación de este tipo de concordancia se cumplen: por un lado, el sustantivo núcleo remite a una realidad incontable de materia - en la que no es pertinente el número de unidades que la componen, de ahí que no esté acompañado de ningún adjetivo numeral o indefinido (...de Ø saya pagizo;...de Ø vaieta negro, etc.) — que se corresponde con tipos distintos de tela o tejido: saya, vaieta/baeta, lana, seda, sarga, sempiterna y mantilla. Excepcionalmente, en el ejemplo número 3, ese sustantivo remite a la realidad 
incontable del agua. Por otro lado, el adjetivo —en todos los casos calificativo- que expresa en su significante el rasgo continuo del sustantivo aparece pospuesto. Este remite en todos los ejemplos — quitando el número 3: agua bendito - a un tipo de color: negro, blanco, morado, encarnado y pagizo.

- Todos los sustantivos núcleos del sintagma son femeninos singulares (una facha, una mantilla, una cuerda, etc.) o masculinos y femeninos plurales (unos trapos, dos fachas...), en cualquier caso contables, por lo que no cabe ninguna duda de que el adjetivo con la marca de «neutro» es término adyacente del segundo sustantivo y no del primero o núcleo sintagmático; es decir: una mantilla de vaieta negro $\rightarrow$ TAdy $+\mathrm{N}+$ TAdy $[$ TR $+\mathrm{N}+$ TAdy $]$ y no $\rightarrow *$ TAdy $+\mathrm{N}+$ TAdy $[$ TR $+\mathrm{N}]$ + TAdy. No obstante, en nuestro corpus de trabajo encontramos algún caso — como los números 2, 17, 72, 76 y 78-, con una variante morfosintáctica con respecto a los casos de este primer tipo estudiado, que consiste en la ausencia de un primer adjetivo numeral o indefinido como TAdy antepuesto que determine el número de unidades del sustantivo núcleo:

2 - Traia unas mangas y almilla de seda viejo, guardapies de droguete y unas medias azules embuelto el cuerpo en un pedazo de cobertor encarnado viejo (f-281, AHA-14006, as.1773-1775).

17 - Traia escofieta, pañuelo, mantilla de cien ilos vieja y pagiza, faxa de ilo ancha y asergada con remates de cinta blanco (f-100, AHA-14010, as.1780-1782).

72 - Embuelto en un mandil de sempiterna viejo, un pedazo de colcha, cinta de lana blanco con su remate de cordel (f-140, AHA-14019, as.1794-1796).

76 - facha de sarga blanco y faxa de punto (f-106, AHA-14021, as.1796-1797).

78 - Embuelta en un pedazo de saya de sarga azul cinta de baeta pagizo (f-134, AHA-14021, as.1796-1797).

En los casos 72 y 78, tanto el sustantivo que es núcleo del sintagma como el que es término adyacente de este son incontables y de materia; así, si tenemos en cuenta también la movilidad del adjetivo dentro del sintagma, podemos entrever que es posible establecer la concordancia continua con cualquiera de los dos nombres, es decir $\rightarrow \mathrm{N}+$ TAdy [TR + N + TAdy] («cinta de lana blanco») o N + TAdy + TAdy («cinta de lana blanco»: lo blanco es la cinta de lana). Los ejemplos número 2, 17 y 76 no ofrecen ningún tipo de duda en cuanto a su interpretación pues, pese a que el sustantivo que es núcleo del sintagma carece de un actualizador que determine el número exacto de unidades, el hecho de que esté en número plural (en el 17) y de que 
sea una referencia contable y específica - [trae una] facha con la que viene vestido el expósito, y no otra facha- (en el caso 76) ya invalida una posible concordancia con el adjetivo que lleva la marca del «neutro».

También con una estructura análoga a estas últimas $(\mathrm{N}+\mathrm{TAdy}$ [TR + N + TAdy]) podemos interpretar los ejemplos 24 y 81 , donde $\mathrm{N}$ es un pronombre que remite a dos sustantivos contables (faxa y mantillas) respectivamente:

24 - Con facha de baeta encarnado vieja dos mantillas escofieta pañuelo, faxa de punto y otra de grana encarnado (f-174, AHA-14011, as.1782-1784).

81 - Lleva tres mantillas una de paño blanco i otra de lana negro un orillo de paño i unas mangas verdes (f-92, AHA-14023, as.1797-1799).

- Otra variante morfosintáctica con respecto a este primer tipo sintagmático la representan los ejemplos número 32 y 82 :

32 - Embuelto en una facha azul vieja traia su gorro negro con una figua, una cinta de orilla de paño y en ella un poco de gasa blanco (f-37, AHA-14012, as.1784-1786).

82 - ...una faja de mediana una escofietina con encage rota y un pañuelin de morles con un poco de beatilla viejo por la garganta (f-275, AHA-14023, as.1797-1799).

Ante la estructura N + TAdy [TR + N + TAdy], N es ahora una estructura pseudopartitiva (RAE 2010: 368) integrada por el cuantificador «poco» y seguida de un término subordinado cuyo núcleo ha de ser un sustantivo incontable (en este caso, gasa y beatilla, de nuevo dos tipos de tejido).

- Por su parte, en el ejemplo 37-Embuelta en unos trapos de mandil y baeta encarnado ligada con una cinta de orilla de somonte (f-154, AHA-14012, as.17841786), tenemos una estructura que introduce una variante con respecto al tipo sintagmático propuesto como base, siendo ahora $\rightarrow$ TAdy $+\mathrm{N}+$ TAdy $[\mathrm{TR}+\mathrm{N}+\underline{\mathrm{N}}+\mathrm{TAdy}]$. $\mathrm{El}$ adjetivo con la marca de neutro (encarnado) remite a un núcleo formado por dos sustantivos continuos coordinados (de mandil y baeta...) en los que, pese a referir dos realidades con géneros distintos, sigue prevaleciendo el rasgo de continuidad de ambas, por eso $\rightarrow$ de mandil y baeta encarnado y no $\rightarrow *$ de mandil y baeta encarnados.

- Todas las marcas del morfema de continuidad se manifiestan en adjetivos. No se documenta, con esta estructura sintagmática, ningún caso con otro tipo de categoría susceptible de reflejarlo, como son los referentes pronominales. 


\section{Tipo 2: TAdy $+\mathbf{N}+$ TAdy $_{[T R}+\mathbf{N}+$ TAdy $]_{+}+$TAdy $_{\text {simple }} /$ TAdy $+\mathbf{N}+$ TAdy $_{\text {simple }}$ + TAdy [TR + N + TAdy]}

7 - Embuelta en una mantilla de baeta pagizo nueva (f-55, AHA-14008, as.1777-1778).

9 - Traia tres mantillas de baeta pagizo nuebas... (f-128, AHA-14008, as.1777-1778).

10 - Embuelto en una mantilla de baeta pagizo nueba y un pedazo de mandil viejo con una cinta baquera (f-132, AHA-14008, as.1777-1778).

11 - Embuelto en unos trapos viejos de baeta pagizo (f-220, AHA-14008, as.1777-1778).

12 - Embuelta en unas mantillas viejas de baeta berde y ceñida con una cinta de seda blanco vieja (f-240, AHA-14008, as.1777-1778).

13 - Venia embuelto en una mantilla de baeta pagizo nueba y faxado con un pedazo de encage viejo (f-247, AHA-14008, as.1777-1778).

20 - Embuelta en una facha vieja de baeta encarnado y una cinta de orilla de paño (f-292, AHA-14010, as.1780-1782).

23 - Con facha de baeta encarnado vieja dos mantillas escofieta pañuelo, faxa de punto y otra de grana encarnado (f-174, AHA-14011, as.1782-1784).

36 - Embuelta en una facha de baeta encarnado bieja, 4 pañales y un pedazo de saya de sempiterna verde con una cinta de paño» (f-134, AHA-14012, as.1784-1786).

39 - Embuelto en una facha vieja de sarga blanco ligado con una trenza pastora angosta (f-262, AHA-14012, as.1784-1786).

41 - Embuelto en unas mantillas de baeta pagizo usadas (f-221, AHA-14013, as.1786-1788).

44 - Embuelto en tres fachas de baeta pagizo viejas, la una guarnecida de cadarzo blanco (f-341, AHA-14013, as.1786-1788).

45 - Embuelta en dos mantillas nuevas de baeta pagizo ligada con una faxa de punto (f-364, AHA-14013, as.1786-1788).

46 - Embuelto en dos mantillas nuevas de baeta pagizo, faxa de punto con una tarjeta o moneda de cobre presa con un lazo de liston encarnado y lo mismo la escofieta y unas callas de mediana atadas con un gordon (f-378, AHA-14013, as.1786-1788).

53 - Embuelta en dos pedazos de baeta pagizo nuevos (f-58, AHA-14015, as.1790-1791).

57 - Embuelto en dos mantillas de baeta pagizo nuebas su escofieta y cinta de paño (f-265, AHA-14015, as.1790-1791).

64 - Embuelta en una mantilla de baeta blanco nueba y cosida al medio (f-184, AHA-14017, as.1791-1793). 
66 - Embuelta en unas mantillas viejas de estameña blanca [la cédula original pone estameña blanco] (f-222, AHA-14017, as.1791-1793).

68 - Embuelto en dos fachas de baeta pagizo nuebas y dos pañales atados con dos gordones de ilo (f-335, AHA-14017, as.1791-1793).

73 - Embuelta en unas mantillas nuevas de baeta blanco gorro nuevo de seda negro siete pañales cinta de orilla de paño y el santiago de plata que dice la papeleta (f-245, AHA-14019, as.1794-1796).

79 - ...para sus señas lleva dos fachas nuebas de baeta pagizo (f-224, AHA-14021, as.1796-1797).

- La estructura sintagmática de estos ejemplos es la siguiente: un núcleo sustantivo (pedazos, mantilla, mantillas, fachas, trapos etc.) acompañado de un término adyacente antepuesto que se corresponde con un adjetivo calificativo numeral (una, dos, tres) o indefinido (unos, unas). Pospuestos al sustantivo núcleo encontramos otros dos términos adyacentes cuyo orden puede variar: un adjetivo calificativo y un sintagma nominal, transpuesto a categoría adjetiva por una preposición (en los ejemplos propuestos, siempre de), y que consta, a su vez, de un sustantivo en función de núcleo y un adjetivo en función de término adyacente que es el que muestra la marca del continuo o «neutro de materia» $(-o)$.

- Como en el tipo sintagmático anterior, se dan los dos condicionantes necesarios para la realización de las concordancias de «neutro»: por un lado, el sustantivo núcleo remite a realidades incontables o de materia que, como ya vimos, tienen que ver con tipos de tela o tejido (baeta, seda, estameña o sarga). Que el género de estos sustantivos sea el femenino impide de manera clara interpretar la marca -o del adjetivo concordado como un masculino singular castellano, en vez del continuo asturiano. Por otro lado, el adjetivo — en todos los casos calificativo - que expresa en su significante el rasgo continuo del sustantivo aparece pospuesto. Este vuelve a remitir en todos los ejemplos a un tipo de color: pagizo, blanco, negro, encarnado...

- La movilidad del adjetivo dentro del grupo sintagmático da lugar a dos tipos de construcciones: una en la que el término adyacente que convenimos en denominar «simple» aparece inmediatamente pospuesto al sustantivo núcleo (dos fachas nuebas de baeta pagizo) y otra en la que este término adyacente aparece en la última posición de la subordinación, después del otro término adyacente — complejo- en el que se muestra la concordancia neutra (una mantilla de baeta blanco nueva; dos fachas de baeta pagizo nuevas). En la primera de ellas no cabe, naturalmente, ningún tipo de duda acerca de la concordancia en género (masculino o femenino) y número (singular 
o plural) con el sustantivo que es núcleo de todo el sintagma. En la segunda de ellas, la posición de ese adjetivo, inmediatamente posterior al sustantivo y al adjetivo que refleja la marca neutra, podría ofrecer alguna duda que, de todas formas, queda resuelta enseguida si tenemos en cuenta que:

a) Cuando el sustantivo que es núcleo de toda la estructura y el sustantivo que es núcleo solo del sintagma nominal que funciona a su vez como TAdy del primero no coinciden en género y/o número, los morfemas del adjetivo TAdy simple $_{\text {s }}$ son el reflejo siempre de la concordancia con el primero de los sustantivos: dos pedazos de baeta pagizo nuevos, dos fachas de baeta pagizo nuevas, etc.

b) Cuando ambos sustantivos sí coinciden en género y número, el adjetivo que

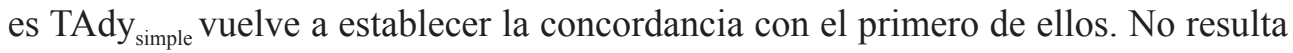
coherente desde el punto de vista semántico — además de que no sería gramaticalpensar que dicho adjetivo podría ser término del segundo sustantivo, dando lugar a dos tipos de concordancias distintas, la asturiana — con la interpretación semántica de la continuidad del sustantivo y, por ende, con la marca del neutro -o en uno de los adjetivos - y la castellana: una mantilla de baeta blanco nueva. Pero no *una mantilla de baeta blanco nueva.

- Un comentario aparte merece el ejemplo número 66, por las implicaciones de tipo sociolingüístico que se desprenden: embuelta en unas mantillas viejas de estameña blanca [la cédula original pone estameña blanco] (f-222, AHA-14017, as.1791-1793). Ya se apuntó que la lengua de los Libros de los Expósitos era el castellano; un castellano, de todas formas, salpicado de numerosas interferencias de la lengua asturiana. El análisis de esta lengua escrita nos muestra que, cuando los copistas habían de transcribir las cédulas con las que en muchas ocasiones aparecían los expósitos en el torno - y que se conservan en cierta medida-, lo hacían castellanizando los rasgos asturianos más sobresalientes, fruto de una conciencia más o menos diglósica. Uno de estos casos es el que encontramos en el ejemplo 66: la cédula original que se conserva con la que el expósito llegó al Hospicio reza: emt ${ }^{a}$ en unas mantillas de estameña blanco biejas... En ella advertimos la presencia del neutro de materia en la forma estameña blanco. Sin embargo, la transcripción que se hace de esta cédula en la entrada correspondiente del expósito en cuestión es: embuelta en unas mantillas viejas de estameña blanca, donde se ha sustituido la expresión de la continuidad para restablecer la concordancia en género y número (femenino singular) que exige el castellano.

- Como variante morfosintáctica de este segundo tipo sintagmático propuesto tenemos el caso número 25-Traia saya mantilla y almilla nuebos de baeta encarnado $\left(\mathrm{f}-202\right.$, AHA-14011, as.1782-1784) $\rightarrow \mathrm{N}+\mathrm{N}+\mathrm{N}+\mathrm{TAdy}_{\text {simple }}+$ TAdy [TR + N + TAdy], donde la presencia de tres núcleos coordinados del sintagma no afecta en 
nada a la concordancia posterior establecida en el TAdy complejo entre el sustantivo incontable baeta y el adjetivo encarnado.

\section{Tipo 3: (TAdy) + N + TAdy [TR + N + (N) + TAdy + TAdy $]$}

28 - Embuelto en unos trapos de mandil y baeta pagizo y encarnado (f-249, AHA-14011, as.1782-1784).

34 - Embuelta en un pedazo de manta viejo atada con una cuerda de lana blanco hermano de la que trae la compañera (f-236, AHA-14012, as.1784-1786).

58 - Asimismo traia un medio naype preso con un liston (angosto) de seda encarnado y nuevo (f-294, AHA-14015, as.1790-1791).

62 - Con un 4 de espadas, con faxa de lana negro y blanco (f-110, AHA-14017, as.1791-1793).

70 - Embuelto en unos trapos de estameña negro y azul (f-151, AHA-14018, as.1793-1794).

77 - Embuelta en unos pedazos de baeta negro y pagizo, cinta baquera (f-109, AHA-14021, as.1796-1797).

- La estructura sintagmática de estos ejemplos es la siguiente: un núcleo sustantivo (pedazos, faxa, trapos, liston, cuerda) acompañado de un término adyacente antepuesto (excepto en el número 62) que se corresponde con un adjetivo calificativo numeral (una) o indefinido (unos). Pospuesto al sustantivo núcleo encontramos otro término adyacente: un sintagma nominal, transpuesto a categoría adjetiva por una preposición (en los ejemplos propuestos, siempre de), y que consta, a su vez, de un sustantivo en función de núcleo y dos adjetivos coordinados en función de término adyacente que son los que muestran la marca del continuo o «neutro de materia» $(-o)$.

- Como en los tipos sintagmáticos anteriores, vuelven a cumplirse los condicionantes necesarios para la aparición de las concordancias de «neutro de materia»: el sustantivo núcleo es objeto de la interpretación semántica continua, esto es, como una realidad no contable; y los adjetivos que expresan en su significante mediante el morfema - $o$ esta referencia aparecen pospuestos

- La coordinación entre ambos adjetivos con la marca de neutro - $o$ refuerza la relación de estos con el sustantivo continuo respectivo. De todas formas, no es necesaria la coordinación, como se demuestra en el ejemplo 34 (una cuerda de lana blanco hermano de...), para mantener en el segundo adjetivo la concordancia continua. La oposición entre este ejemplo y los comentados en el tipo sintagmático 2 (una mantilla de baeta blanco nueva) es evidente: ante la misma posición sintagmática, solo el tipo de concordancia y su expresión diferenciada nos hace ver que en 34 el 
adjetivo hermano concuerda con el sustantivo que es núcleo del término adyacente, mientras que en el tipo una mantilla de baeta blanco nueva el adjetivo nueva solo puede ser término subordinado del sustantivo núcleo de todo el sintagma. También en el ejemplo 34 encontramos un caso de referente pronominal cuya marca esperable habría de ser la neutra pero que, sin embargo, no es así: una cuerda de lana blanco hermano de la que trae la compañera. La concordancia plena del «neutro de materia» exigiría a su vez una forma pronominal «lo» (D’Andrés Díaz 1993: 77). La razón de este cambio probablemente haya que buscarla en una pérdida o dilución de la interpretación semántica del sustantivo lana como realidad continua de materia y no contable, favorecida tanto por la «lejanía» del pronombre con respecto a su referente dentro de la oración como por la presión castellanizante.

- En lo que respecta al ejemplo número 70 (unos trapos de estameña negro y azul), el segundo de los adjetivos, aunque invariable y sin expresión diferenciada de la concordancia neutra, también ha de considerarse como término adyacente del sustantivo continuo estameña, tanto por la coordinación con el adjetivo negro, que sí expresa la marca neutra, como por ser imposible la concordancia con el sustantivo núcleo de todo el sintagma (trapos), que es masculino y plural.

- En el ejemplo 28, la explicación morfosintáctica que se ofrece es la misma que la del caso $\mathrm{n}^{\mathrm{0}} 37$, comentado dentro del tipo sintagmático 1 . Los adjetivos con la marca de neutro (pagizo y encarnado) remiten a un núcleo formado por dos sustantivos continuos coordinados (de mandil y baeta...) en los que, pese a referir dos realidades con géneros distintos, sigue prevaleciendo el rasgo de continuidad de ambas, por eso $\rightarrow$ de mandil y baeta pagizo y encarnado y no $\rightarrow *$ de mandil y baeta pagizos $y$ encarnados.

\section{Tipo 4: $($ TAdy $)+N$ + TAdy [TR + (TAdy) + N + TAdy [TR + N + TAdy] $]$}

5 - Embuelta en unos pañales de olanda con un pañuelo de tres puntas y tres callas de lo mismo usadas (...) y sobre todo una mantilla de lienzo pintado aforrada con baeta blanco y en la cabeza dos escofietas con guirindola o bollos de cinta de seda encarnado (f-227, AHA14007, as.1775-1777).

48 - Embuelta en un paño de una basquina de estameña viejo, dos pañales y pañuelo con una cinta de dos generos (f-104, AHA-14014, as.1788-1790).

50 - Embuelto en un pedazo de saya de baeta encarnado su pañuelo y cinta de paño (f-249, AHA-14014, as.1788-1790). 
60 - Embuelta en un pedazo de saya de baeta viejo un mandil de chalon ligada con una tira de mediana (f-307, AHA-14015, as.1790-1791).

- Los condicionantes de aparición del neutro de materia vuelven a cumplirse como en los anteriores tipos sintagmáticos propuestos: sustantivo incontable de interpretación semántica continua (seda, estameña y baeta) y adjetivo en posición posnuclear (viejo y encarnado). La recursividad que se muestra en este grupo de ejemplos no repercute o afecta a la concordancia neutra que se establece en el último de los TAdy.

\section{Otros:}

1 - ... Traia una cinta de 3 varas de Rera [sic] tres pedazos de baieta pajiza un pañal de lienzo una camisa y una cofia en la caveza, dicha ropa todo mui usado (f-163, AHA-13999, as.1758-1764).

4 - Embuelta en unos pañales de olanda con un pañuelo de tres puntas y tres callas de lo mismo usadas (...) y sobre todo una mantilla de lienzo pintado aforrada con baeta blanco y en la cabeza dos escofietas con guirindola o bollos de cinta de seda encarnado (f-227, AHA14007, as.1775-1777).

14 - Embuelta en un pedazo de sarga y baeta pagizo viejo (f-44, AHA-14010, as.1780-1782).

47 - esta niña esta bautizada y se llama Benita Josefa y tambien con una cuenta de azebache negro y un pedazo de manta de color de sangre podrido (f-51, AHA-14014, as.1788-1790).

61 - Embuelto en dos buenas mantillas de miliqui encarnado con cinta pagizo (f-105, AHA14017, as.1791-1793).

65 - ...gorro de lienzo con blonda negro... (f-187, AHA-14017, as.1791-1793).

69 - Traia un gorro de tafetan azul, guarnecido con gasa negro (f-47, AHA-14018, as.1793-1794).

- Los casos 61 y 65 parten de una estructura sintagmática similar a la del tipo 1 - ...N... + TAdy [TR + N + TAdy]- y de los mismos factores necesarios que condicionan la aparición del neutro: sustantivo incontable (cinta, blonda) y adjetivo pospuesto (pagizo, negro). La única diferencia ahora consiste en la preposición que introduce el TAdy del núcleo sintagmático: con.

- En los ejemplos 4 y 69 las concordancias de neutro que se establecen no difieren de otros casos ya estudiados, tan solo varía la estructura sintagmática en la que se encuentran. En ambos ejemplos se reconoce una forma básica de...N...+ TAdy [N + Complemento Circunstancial] en la que TAdy es un participio con función nominal 
a nivel oracional, pero función verbal a nivel suboracional: ...mantilla ...aforrada con baeta blanco $;. .$. gorro... guarnecido con gasa negro.

- En cuanto al caso número 14, la interpretación morfosintáctica lógica que se deduce de su análisis nos hace pensar en una estructura sintagmática como la del tipo 3: TAdy $+\mathrm{N}+$ TAdy $[\mathrm{TR}+\mathrm{N}+\mathrm{N}+\underline{\mathrm{TAdy}}+\mathrm{TAdy}]$, en la que los adjetivos con la marca de neutro (pagizo viejo) remiten a un núcleo formado por dos sustantivos continuos coordinados (de sarga y baeta...) en los que prevalece el rasgo de la continuidad. De todas formas, dada la movilidad de los adjetivos dentro de la frase y el hecho de que el núcleo sintagmático (pedazo) es en este caso un sustantivo masculino singular - y, por lo tanto, con un morfema coincidente con el continuo asturiano-, no deja de ser factible una posible interpretación de la estructura, ya sin concordancia de neutro, como: TAdy + N + TAdy [TR + N + N] + TAdy + TAdy («un pedazo de sarga y baeta pagizo viejo »). Al respecto de este tipo de casos se dedicarán unas reflexiones al final de este apartado.

- El primero de los ejemplos constituye una muestra clara de las restricciones y los factores que condicionan la aparición del neutro: frente a la concordancia continua que demuestran los términos pospuestos (todo mui usado), el adjetivo que se halla en posición prenuclear restablece la concordancia en género y número propia del sustantivo núcleo: dicha ropa ${ }^{8}$. Además, es este el único de los casos que parece admitir una interpretación atributiva o predicativa, con elisión del verbo principal, y no nominal, de los términos que reflejan la continuidad del sustantivo: dicha ropa [está, viene...] todo mui usado.

Una vez analizados los 82 casos iniciales propuestos para el estudio morfosintáctico, podemos apuntar una serie de conclusiones:

- Desde el punto de vista semántico, los sustantivos que son objeto de la concordancia neutra tienen un carácter continuo, indeterminado en cuanto al número de unidades componentes, que remiten en su mayoría a tipos de tela o de tejido: baeta, sarga, estameña, lana, etc. Además de estos, aparecen otros tres sustantivos como agua, ropa y sangre cuyo rasgo de continuidad también favorece la concordancia de «neutro de materia». En cuanto al adjetivo, es precisamente en la concordancia con estos tres sustantivos, cuando aparece el de tipo participial o perfectivo: usado, bendito, podrido.

Para una posible explicación sintáctica, desde la gramática generativista, acerca de la relación entre el tipo de concordancia del adjetivo y su posición en la oración puede leerse Matthew Burner (2016). 
- La estructura sintagmática que más veces se repite es la del tipo 1 y sus variantes, con un 52' $4 \%$ de casos ( 43 de los 82 ejemplos estudiados), seguida del tipo 2, con un 26 ' $8 \%$ de casos y 22 ejemplos en total. En general, y tomando como referencia el grupo nominal mínimo en el que se encuentra la concordancia neutra, predominan las estructuras sencillas y repetitivas de sust $+d e+s u s t+a d j$, que parecen seguir un modelo de escritura descriptiva ya fijado o preestablecido. De hecho, a lo largo de los casi 50 años que comprende el corpus textual, las descripciones que se realizan de la ropa de los expósitos son muy similares en fondo y forma, pese a que los amanuenses de estos documentos sí fueron cambiando en esos años, como demuestran los distintos tipos de letra. En muy pocas ocasiones hay más de una concordancia neutra en la misma estructura, quitando los 6 casos del tipo 3, con dos adjetivos coordinados. Precisamente, es en una de estas estructuras más «complejas» (34 - Embuelta en un pedazo de manta viejo atada con una cuerda de lana blanco hermano de la que trae la compañera) en la que el último de los términos susceptibles de realizar la concordancia neutra ya pierde la referencia continua. No hay que olvidar que, por lo general, el registro de la información en estos Libros de los Expósitos tiende a formas de escasa complejidad sintáctica, por lo que se restringe la posibilidad de encontrar concordancias de neutro en demostrativos, referentes átonos, etc.

- De los 82 casos de «neutro de materia» analizados, un total de 81 aparecen en función nominal como complementos del nombre, frente a solo 1 caso que se registra en función atributiva o predicativa, con elisión del verbo principal (dicha ropa todo mui usado). Esto contrasta con los resultados obtenidos por Fernández Ordoñez (2007b) quien, a través del análisis de los ejemplos de «neutro de materia» que aparecen en algunas de las monografías dialectales del asturiano de la segunda mitad del siglo XX, observa que:

...la concordancia continua se presenta preferentemente en atributos acompañados por el verbo ser, en adjetivos y participios acompañados por el verbo estar o en adjetivos predicativos. Esto es, aparece de forma predominante cuando el adjetivo restringe la denotación del nombre a través de la intermediación del verbo (55 casos, 68,7\%). En cambio, su frecuencia en adjetivos calificativos que predican propiedades del nombre directamente, en el interior de un sintagma nominal, parece mucho menor ( 25 casos, $31,2 \%)(\ldots)$ Este comportamiento sintáctico sugiere que la concordancia de materia se manifestará de forma más estable en las posiciones predicativas y que, si se pierde, desaparecerá antes cuando funciona como adjunto del nombre (Fernández-Ordóñez 2007b: 403, 405). 
Hay que tener en cuenta, no obstante, que los ejemplos que maneja FernándezOrdóñez de las distintas monografías proceden de la lengua oral o, al menos, pretenden reflejar los usos orales, frente a los ejemplos estudiados aquí, que proceden de la lengua escrita y, por tanto, tienen unos usos fijados y determinados que no concuerdan con la espontaneidad propia de la oralidad. De todas formas, la plasmación escrita de este fenómeno había de responder a un uso frecuente en el ambiente y tan interiorizado que incluso un copista con la intención de escribir en lengua castellana no pudo identificarlo para eliminarlo. La gran cantidad de ejemplos de esta concordancia en el adjetivo en función nominal sugiere que no habría de resultar disonante y su uso espontáneo podría ser más común de lo que Fernández-Ordóñez destaca.

- En los 47 años que comprende nuestro corpus textual (de 1752 a 1799), la mayor parte de casos de «neutro de materia» aparecen concentrados en la década de 1780, y seguirán documentándose en décadas posteriores aunque en mucha menor medida. Más que relacionar este hecho con un posible factor temporal y una mayor o menor vitalidad del fenómeno - lo que no tiene mucho sentido, dado que sigue siendo un rasgo muy común tanto en el asturiano de hoy como, por interferencia de este, en el castellano de Asturies - resulta más apropiado vincular la aparición de esta interferencia con la persona o personas que en cada momento estuvieran al cargo de la escritura de estos Libros de los Expósitos, aunque nada sepamos del contexto de dichos copistas: origen, formación, mayor o menor conciencia diglósica y de conocimiento de asturiano y castellano, etc. Pese a la frecuencia de este fenómeno en los años estudiados, es interesante destacar también que no siempre que el contexto semántico y sintáctico es propicio se produce la concordancia neutra, como demuestran las concordancias de género y número que se recogen ante las mismas estructuras sintagmáticas: un lazo de cinta de seda encarnada cosido en ella (f-379, AHA-14011, as.1782-1784); ...guarnecida con un liston de seda encarnada (f-50, AHA-14017, as.1790-1791); Embuelto en una mantilla nueba de baeta pagiza ligado con unas trenzas pastoras (f-282, AHA-14017, as.1791-1793), etc.

Junto a los ejemplos claros de «neutro de materia» revisados hasta aquí, también encontramos en nuestro corpus textual otras construcciones cuya interpretación morfosintáctica resulta más dudosa. Son casos como: Embuelta en un pedazo de sarga viejo ligada con una cinta baquera tambien vieja (f-86, AHA-14008, as.1777-1778); Traia una escofieta con guirindola atada con un ylo de lana encarnado y faxado con una cinta de paño (f-20, AHA-14010, as.1780-1782); Embuelta en un pedazo de saya pagizo y viejo ligada con una faxa de paño verde, escofieta con encage apretador y pañuelo (f-154, AHA-14011, as.17882-1784); Embuelta en un dengue de baeta negro y un pañal por la cabeza (f-25, AHA-14012, as.1784-1786); Lleba vestido un mandil 
de estameña negro con cinta, otro de sarga blanco, un pañal y otro por la cabeza y una cinta de paño con remates de cadarzo (f-147, AHA-14012, as.1784-1786) ${ }^{9}$, etc.

El problema de interpretación que presentan estos ejemplos reside en dos cuestiones: por un lado, la movilidad del adjetivo dentro del grupo nominal y, por otro, la coincidencia de significante entre el morfema de masculino singular en castellano y el de continuo en asturiano $(-o)$, siendo el núcleo de los sintagmas propuestos un sustantivo masculino singular (mandil, pedazo, ylo, dengue...). Frente a los ejemplos estudiados como muestra de la concordancia de neutro, que constan siempre de un sustantivo núcleo femenino contable y un sustantivo como complemento también femenino pero no contable — por lo que es evidente que la concordancia del adjetivo en -o se hace con este último (una cuerda de lana blanco) - , ahora no hay forma de saber con qué sustantivo está concordando el adjetivo y, por ende, ante qué tipo de concordancia estamos: la asturiana (un mandil de estameña negro $\rightarrow$ TAdy $+\mathrm{N}+$ TAdy $[\mathrm{TR}+\mathrm{N}+\mathrm{TAdy}]$ ) o la castellana (un mandil de estameña negro $\rightarrow$ TAdy $+\mathrm{N}$ + TAdy $[\mathrm{TR}+\mathrm{N}]+$ TAdy $)^{10}$. Es legítimo pensar que pueda ser cualquiera de las dos:

- La asturiana, porque ya hay documentados muchos casos de neutro de materia; además, cuando en la estructura hay solo un adjetivo, no suele registrarse la secuencia tipo un mandil negro de estameña, sino un mandil de estameña negro; por otra parte, en los ejemplos en los que la concordancia es la castellana (un lazo de cinta de seda encarnada cosido en ella [f-379, AHA-14011, as.1782-1784]), vemos que el adjetivo concuerda con el sustantivo no contable, por lo que también podrían interpretarse así estos otros casos en cuestión.

- La castellana, porque no siempre que es posible la concordancia de neutro, se produce: ...guarnecida con un liston de seda encarnada (f-50, AHA-14017, as.1790-1791), Embuelto en una mantilla nueba de baeta pagiza ligado con unas trenzas pastoras (f-282, AHA-14017, as.1791-1793), etc.; o porque se registra alguna secuencia sintagmática en la que el único adjetivo, en última posición, sí concuerda con

$\overline{9} \quad$ En el anexo final se relacionan un total de 24 casos como estos.

10 Somos conscientes de que esta asociación puede resultar algo simplista y entrañar algún problema pues, por un lado, la no concordancia neutra es válida y posible en asturiano y, por otro, la concordancia neutra también es perfectamente documentable en castellano (véanse los ejemplos, muy similares a los que se presentan aquí, de Gómez Seibane y Vázquez Balonga 2013 y Morala Rodríguez 2015). De todas formas, las características de la documentación con la que trabajamos nos hacen defender firmemente la idea de que las construcciones con neutro que aparecen en estos Libros de los Expósitos del Hospicio de Uviéu son, como otros muchos rasgos fonéticos, gramaticales y léxicos que se muestran a lo largo de sus páginas, fruto de la interferencia con la lengua asturiana. 
el sustantivo contable y que es núcleo: Embuelto en dos pedazos de baeta encarnados $y$ viejos (f-110, AHA-14014, as.1788-1790).

No hay que considerar como ejemplos del fenómeno de neutro de materia casos como: Traia una facha encarnado hecha de una saya cofia y escofieta con su faxa de punto (f-35, AHA-14012, as.1784-1786); Embuelta en un mandil y una facha pagizo, escofieta pañuelo y cinta de orilla de paño de colores (f-96, AHA-14012, as.17841786); Embuelto en una facha de sayal 4 o 5 pañales rotos y una trenza negro (f-137, AHA-14012, as.1784-1786), etc. Dejando a un lado el posible error gráfico del copista como causa de estas concordancias «peculiares», resulta más lógico pensar en la elisión de alguna palabra o expresión como: traia una facha [de color] encarnado... Además, en estos casos el sustantivo es claramente contable, por lo que ni siquiera en asturiano rige la concordancia «neutra».

\section{CONCLUSIONES}

El estudio de los casos de «neutro de materia» de los Libros de los Expósitos pone de manifiesto la vitalidad de la que había de gozar este fenómeno en aquella época (siglo XVIII), hasta el punto de interferir en unos textos escritos en lengua castellana, la lengua de prestigio y vehículo comunicativo formal/administrativo. Los factores que condicionan la aparición de este tipo de concordancia, en función de una categoría semántica, son los mismos que se dan en la actualidad y aparecen aquí bien reflejados: rasgo continuo o incontable del sustantivo y posición posnuclear del adjetivo. La mayor parte de las estructuras estudiadas repiten, con variantes, unas mismas secuencias morfosintácticas basadas en la estructura sust $+d e+s u s t+a d j(=\mathrm{N}+$ TAdy [TR $+\mathrm{N}+$ TAdy]), con predominio de la función nominal (y no atributiva o predicativa) del adjetivo que lleva la marca de neutro, lo que parece sugerir unos modelos de escritura repetitivos y predeterminados que los distintos copistas fueron siguiendo a lo largo de los años.

\section{BIBLIOGRAFÍA}

Alla = Academia de la Llingua Asturiana (2001): Gramática de la Llingua Asturiana. Uviéu: Alla, $3^{\text {era }}$ ed.

Alonso, D. (1958): «Metafonía, neutro de materia y colonización suditaliana en la Península hispánica», en Obras completas, vol. 1, Madrid, Gredos, 1972, pp. 147-213 ( $1^{\mathrm{a}}$ ed., con el título «Metafonía y neutro de materia en España (sobre 
un fondo italiano)», Zeitschrift für romanische Philologie 74 (1958), pp. 1-24. https://doi.org/10.1515/zrph.1958.74.1-2.1

ANDRÉs DíAZ, R. D’ (1993): «Emplegu del neutru n’asturianu», Lletres Asturianes 49, pp. 49-84.

Anes Fernández, L. (2000): Pobreza y beneficencia en Asturias en la segunda mitad del siglo XVIII. Oviedo: RIDEA.

ARIas CABAL, A. (1999): El morfema de neutro de materia en asturiano. Santiago de Compostela: Universidade de Santiago de Compostela.

BuRNER, M. (2016): «El neutro de materia en asturiano: Un acercamiento sintáctico al fenómeno en cuanto a la especificidad, genericidad y la posición del adjetivo», Revista de Filoloxía Asturiana 16, pp. 49-62. https://doi.org/10.17811/ rfa.16.2016.49-62

Canellada, M. J. (1944): El bable de Cabranes. Edición facsimilar publicada por la Academia de la Llingua Asturiana, Uviéu, (1996).

CaVeda y Nava, José (1887): Poesías selectas en dialecto asturiano. Reproducción facsimilar de la reimpresión de Uviéu de 1887 editada por Fermín Canella y Secades, Imprenta de Vicente Brid. Uviéu: Academia de la Llingua Asturiana (2003).

Dalla = Academia de la llingua Asturiana (2000): Diccionariu de la Llingua Asturiana. Uviéu: Alla. Consulta en línea (08/03/2019): http://www. academiadelallingua.com/diccionariu/index.php

FERnÁNDEZ-OrdóÑEZ, I. (2006): «Del Cantábrico a Toledo: el «neutro de materia» hispánico en un contexto románico y tipológico», Revista de Historia de la Lengua Española 1, pp. 67-118.

FERnÁNDEZ-OrdóÑEZ, I. (2007a): «Del Cantábrico a Toledo: el «neutro de materia» hispánico en un contexto románico y tipológico» (continuación), Revista de Historia de la Lengua Española 2, pp. 29-81.

FERNÁNDEZ-ORDóÑEZ, I. (2007b): «El «neutro de materia» en Asturias y Cantabria. Análisis gramatical y nuevos datos», en A. Puigvert Ocal \& I. Delgado Cobos (eds.): Ex admiratione et amicitia. Homenaje a Ramón Santiago, Madrid: Ediciones del Orto, pp. 395-434.

García Arias, X. Ll. (2003): Gramática Histórica de la Lengua Asturiana. Uviéu: ALLA.

Gómez Seibane, S. \& D. VÁzquez Balonga (2013): «¿Más huellas del neutro de materia en los Siglos de Oro? Algunos testimonios de la región de Madrid», Revista de Filoloxía Asturiana 13, pp. 53-70. 
LÜDTKE, H. (2003): «El neutro románico: su origen antiguo y sus avatares posteriores en asturiano, castellano norteño, romanche e italiano dialectal», Lletres Asturianes 82 , pp. 7-14.

MARTíNEZ Álvarez, J. (1967): «Bable y castellano en el concejo de Oviedo», separata de Archivum XVII, pp. 5-292.

Menéndez Pidal, R. (1962): El dialecto leonés. Oviedo: Instituto de Estudios Asturianos.

Morala Rodríguez, J. R. (2015): «Datos para la historia del neutro de materia en castellano», Revista de Filología Española XCV, 2º, pp. 307-337. https://doi. org/10.3989/rfe.2015.12

NeIRa MartíneZ, J. (1978): «La oposición continuo/discontinuo en las hablas asturianas», Estudios ofrecidos a Emilio Alarcos Llorach, Oviedo: Universidad de Oviedo, vol. 3, pp. 255-280.

RAE = REAL ACADEMIA ESPAÑOLA DE LA LENGUA (2010): Nueva gramática de la lengua española. Madrid: Espasa.

SAn SEgundo CACHero, R. (2015): «El neutro de materia en la morfología nominal del asturiano del concejo de L.lena», Lletres Asturianes 112, pp. 11-37.

VIEJO FERNÁNDEZ, X. (2003): La formación histórica de la llingua asturiana. Uviéu: Trabe.

VIEJO FERNÁNDEZ, X. (2018): «La morfologización de las armonizaciones vocálicas en el centro de Asturias: innovación y escisión protorromance», Verba 45, pp. 193-224. https://doi.org/10.15304/verba.45.4080

Relación de los Libros de los Expósitos del Archivo Histórico de Asturias empleados: - S.XVIII (23 libros):

AHA-13998 (as.1752-1758); AHA-13999 (as.1758-1764); AHA-14000 (as.1764-1766); AHA-14001 (as.1766-1768); AHA-14002 (as.1768-1769); AHA-14003 (as.1769-1770); AHA-14004 (as.1770-1771); AHA-14005 (as.1771-1773); AHA-14006 (as.1773-1775); AHA-14007 (as.1775-1777); AHA-14008 (as.1777-1778); AHA-14009 (as.1778-1780); AHA-14010 (as.1780-1782); AHA-14011 (as.1782-1784); AHA-14012 (as.1784-1786); AHA-14013 (as.1786-1788); AHA-14014 (as.1788-1790); AHA-14015 (as.1790-1791); AHA-14017 (as.1791-1793); AHA-14018 (as.1793-1794); AHA-14019 (as.1794-1796); AHA-14021 (as.1796-1797); AHA-14023 (as.1797-1799). 


\section{Anexo}

Relación, por orden cronológico, de los 82 ejemplos de «neutro de materia» estudiados:

1 - ...Traia una cinta de 3 varas de Rera [sic] tres pedazos de baieta pajiza un pañal de lienzo una camisa y una cofia en la caveza, dicha ropa todo mui usado (f-163, AHA-13999, as.1758-1764).

2 - Traia unas mangas y almilla de seda viejo, guardapies de droguete y unas medias azules embuelto el cuerpo en un pedazo de cobertor encarnado viejo (f-281, AHA-14006, as.1773-1775).

3 - esta bautizado en la pila del agua bendito de iglesia parrroquial y su nombre es Bentura (f-119, AHA-14007, as.1775-1777).

4 y 5 - Embuelta en unos pañales de olanda con un pañuelo de tres puntas y tres callas de lo mismo usadas (...) y sobre todo una mantilla de lienzo pintado aforrada con baeta blanco y en la cabeza dos escofietas con guirindola o bollos de cinta de seda encarnado (f-227, AHA-14007, as.1775-1777).

6 - Traia dos fachas de baeta pagizo, dos escofietas, la una de lienzo pintado... (f-230, AHA-14007, as.1775-1777).

7 - Embuelta en una mantilla de baeta pagizo nueva (f-55, AHA-14008, as.1777-1778).

8 - Con una papeleta cosida en un liston encarnado con una hebra de seda pagizo, cuya papeleta dezia... (f-91, AHA-14008, as.1777-1778).

9 - Traia tres mantillas de baeta pagizo nuebas... (f-128, AHA-14008, as.1777-1778).

10 - Embuelto en una mantilla de baeta pagizo nueba y un pedazo de mandil viejo con una cinta baquera (f-132, AHA-14008, as.1777-1778).

11 - Embuelto en unos trapos viejos de baeta pagizo (f-220, AHA-14008, as.1777-1778).

12 - Embuelta en unas mantillas viejas de baeta berde y ceñida con una cinta de seda blanco vieja (f-240, AHA-14008, as.1777-1778).

13 - Venia embuelto en una mantilla de baeta pagizo nueba y faxado con un pedazo de encage viejo (f-247, AHA-14008, as.1777-1778).

14 - Embuelta en un pedazo de sarga y baeta pagizo viejo (f-44, AHA-14010, as.1780-1782).

15 - Traia una saya de baeta encarnado, almilla y camisa... (f-102, AHA-14010, as.1780-1782).

16 - Embuelto en una mantilla de baeta pagizo, cinta de paño, escofieta y pañuelo en la cabeza (f-85, AHA-14010, as.1780-1782). 
17 - Traia escofieta, pañuelo, mantilla de cien ilos vieja y pagiza, faxa de ilo ancha y asergada con remates de cinta blanco (f-100, AHA-14010, as.1780-1782).

18 - Traia una saya de baeta encarnado, almilla y camisa... (f-102, AHA-14010, as.1780-1782).

19 - con una saya de baeta encarnado (f-107, AHA-14010, as.1780-1782).

20 - Embuelta en una facha vieja de baeta encarnado y una cinta de orilla de paño (f-292, AHA-14010, as.1780-1782).

21 - Embuelto en una facha de mantilla negro y ligado con una faxa blanca de punto (f-330, AHA-14010, as.1780-1782).

22 - Embuelto en dos fachas de baeta pagizo un pañuelo de mosolina aburillado tres pañales y una faxa de punto (f-49, AHA-14011, as.1782-1784).

23 y 24 - Con facha de baeta encarnado vieja dos mantillas escofieta pañuelo, faxa de punto y otra de grana encarnado (f-174, AHA-14011, as.1782-1784).

25 - Traia saya mantilla y almilla nuebos de baeta encarnado (f-202, AHA-14011, as.1782-1784).

26 - Embuelta en una mantilla de baeta pagizo con su trenza nueba pastora (f-237, AHA-14011, as.1782-1784).

27 - Embuelta en una facha de baeta pagizo y una escofieta atada con una trenza de colores y ligada con una orilla de caldas (f-246, AHA-14011, as.1782-1784).

28 - Embuelto en unos trapos de mandil y baeta pagizo y encarnado (f-249, AHA14011, as.1782-1784).

29 - Embuelta en un pedazo de paño viejo azul unas mangas atadas con una cuerda de lana blanco (f-272, AHA-14011, as.1782-1784).

30 - Lleva para su abrigo y decencia tres pañales una bara de baeta pagizo y tres baras de cinta pastora con dos paños en la cabeza... (f-274, AHA-14011, as.1782-1784).

31 - Embuelto en unos trapos de sempiterna verde y ligado con unas tiras de baeta negro (f-313, AHA-14011, as.1782-1784).

32 - Embuelto en una facha azul vieja traia su gorro negro con una figua, una cinta de orilla de paño y en ella un poco de gasa blanco (f-37, AHA-14012, as.1784-1786).

33 - Embuelta en una facha de lino y lana, 4 pañales y ligada con una tira de baeta negro de cien ilos (f-230, AHA-14012, as.1784-1786).

34 - Embuelta en un pedazo de manta viejo atada con una cuerda de lana blanco hermano de la que trae la compañera (f-236, AHA-14012, as.1784-1786).

35 - Embuelta en dos mantillas de baeta pagizo, gorro de tripe escofieta dos pañales, y una faxa de tienda (f-86, AHA-14012, as.1784-1786).

36 - Embuelta en una facha de baeta encarnado bieja, 4 pañales y un pedazo de saya de sempiterna verde con una cinta de paño (f-134, AHA-14012, as.1784-1786). 
37 - Embuelta en unos trapos de mandil y baeta encarnado ligada con una cinta de orilla de somonte (f-154, AHA-14012, as.1784-1786).

38 - Embuelta en un pedazo de manta viejo y unos trapos de camisa por callas, un repuelgo de saya con una cuerda de lana blanco por cinta (f-191, AHA-14012, as.1784-1786).

39 - Embuelto en una facha vieja de sarga blanco ligado con una trenza pastora angosta (f-262, AHA-14012, as.1784-1786).

40 - Embuelta en unos trapos de baeta encarnado, escofieta y cinta de paño (f-125, AHA-14013, as.1786-1788).

41 - Embuelto en unas mantillas de baeta pagizo usadas (f-221, AHA-14013, as.1786-1788).

42 - Embuelto en tres pedazos de mandil, dos pañales y un pañuelo por bastillar con una tercia de sempiterna negro (f-296, AHA-14013, as.1786-1788).

43 - Embuelta en unos trapos de baeta negro y cinta de paño (f-196, AHA-14013, as.1786-1788).

44 - Embuelto en tres fachas de baeta pagizo viejas, la una guarnecida de cadarzo blanco (f-341, AHA-14013, as.1786-1788).

45 - Embuelta en dos mantillas nuevas de baeta pagizo ligada con una faxa de punto (f-364, AHA-14013, as.1786-1788).

46 - Embuelto en dos mantillas nuevas de baeta pagizo, faxa de punto con una tarjeta o moneda de cobre presa con un lazo de liston encarnado y lo mismo la escofieta y unas callas de mediana atadas con un gordon (f-378, AHA-14013, as.1786-1788).

47 - esta niña esta bautizada y se llama Benita Josefa y tambien con una cuenta de azebache negro y un pedazo de manta de color de sangre podrido (f-51, AHA14014, as.1788-1790).

48 - Embuelta en un paño de una basquina de estameña viejo, dos pañales y pañuelo con una cinta de dos generos (f-104, AHA-14014, as.1788-1790).

49 - Embuelta en una mantilla y una facha de sarga blanco (f-156, AHA-14014, as.1788-1790).

50 - Embuelto en un pedazo de saya de baeta encarnado su pañuelo y cinta de paño (f-249, AHA-14014, as.1788-1790).

51 - Embuelto en una facha de baeta encarnado ligado con una cinta angosta de orilla de paño (f-352, AHA-14014, as.1788-1790).

52 - Embuelto en unos pedazos de baeta negro y una cinta baquera con otros trapos (f-22, AHA-14015, as.1790-1791).

53 - Embuelta en dos pedazos de baeta pagizo nuevos (f-58, AHA-14015, as.1790-1791). 
54 - Embuelto en una mantilla de baeta pagizo y faxa de punto ancha (f-85, AHA14015, as.1790-1791).

55 - ...presos con una ebra de seda morado (f-131, AHA-14015, as.1790-1791).

56 - Embuelta en unos trapos de sayal ligada con una cinta de lana negro (f-214, AHA-14015, as.1790-1791).

57 - Embuelto en dos mantillas de baeta pagizo nuebas su escofieta y cinta de paño (f-265, AHA-14015, as.1790-1791).

58 - Asimismo traia un medio naype preso con un liston angosto de seda encarnado y nuevo (f-294, AHA-14015, as.1790-1791).

59 - Embuelta en unos trapos de cobertor ligada con una tira de baeta blanco (f-302, AHA-14015, as.1790-1791).

60 - Embuelta en un pedazo de saya de baeta viejo un mandil de chalon ligada con una tira de mediana (f-307, AHA-14015, as.1790-1791).

61 - Embuelto en dos buenas mantillas de miliqui encarnado con cinta pagizo» (f-105, AHA-14017, as.1791-1793).

62 - Con un 4 de espadas, con faxa de lana negro y blanco (f-110, AHA-14017, as.1791-1793).

63 - Embuelto en una facha de baeta blanco gorro de lienzo y ligado con un cadarzo de dos generos (f-166, AHA-14017, as.1791-1793).

64 - Embuelta en una mantilla de baeta blanco nueba y cosida al medio (f-184, AHA14017, as.1791-1793).

65 - ...gorro de lienzo con blonda negro... (f-187, AHA-14017, as.1791-1793).

66 - Embuelta en unas mantillas viejas de estameña blanca [la cédula original pone estameña blanco] (f-222, AHA-14017, as.1791-1793).

67 - Embuelto en unos trapos de mediana atados con una cuerda de lana blanco y una tira de camisa con un boton» (f-295, AHA-14017, as.1791-1793).

68 - Embuelto en dos fachas de baeta pagizo nuebas y dos pañales atados con dos gordones de ilo (f-335, AHA-14017, as.1791-1793).

69 - Traia un gorro de tafetan azul, guarnecido con gasa negro (f-47, AHA-14018, as.1793-1794).

70 - Embuelto en unos trapos de estameña negro y azul (f-151, AHA-14018, as.1793-1794).

71 - Llamome Nicolasa, nazi al tercero para las doce de oy 5 de Diz de 93, no estoy bautizada llebo dos fachas de vayeta pagizo por hazer... (f-155, AHA-14018, as.1793-1794).

72 - Embuelto en un mandil de sempiterna viejo, un pedazo de colcha, cinta de lana blanco con su remate de cordel (f-140, AHA-14019, as.1794-1796). 
73 - Embuelta en unas mantillas nuevas de baeta blanco gorro nuevo de seda negro siete pañales cinta de orilla de paño y el santiago de plata que dice la papeleta (f-245, AHA-14019, as.1794-1796).

74 - Embuelta en una facha de baeta morado con una tira de terliz (f-92, AHA-14021, as.1796-1797).

75 - Embuelta en unos trapos de saya pagizo cinta de baeton y un gordon de seda (f-104, AHA-14021, as.1796-1797).

76 - facha de sarga blanco y faxa de punto (f-106, AHA-14021, as.1796-1797).

77 - Embuelta en unos pedazos de baeta negro y pagizo, cinta baquera (f-109, AHA14021, as.1796-1797).

78 - Embuelta en un pedazo de saya de sarga azul cinta de baeta pagizo (f-134, AHA14021, as.1796-1797).

79 - ...para sus señas lleva dos fachas nuebas de baeta pagizo (f-224, AHA-14021, as.1796-1797).

80 - Traia vestido una mantilla de vaieta negro, escofieta una faja de pelusa encarnada (f-292, AHA-14021, as.1796-1797).

81 - Lleva tres mantillas una de paño blanco i otra de lana negro un orillo de paño i unas mangas verdes (f-92, AHA-14023, as.1797-1799).

82 - ...una faja de mediana una escofietina con encage rota y un pañuelin de morles con un poco de beatilla viejo por la garganta (f-275, AHA-14023, as. 1797-1799).

Relación de ejemplos de interpretación dudosa:

1 - Embuelta en un pedazo de baeta negro viejo (f-257, AHA-14007, as.1775-1777).

2 - Embuelta en un pedazo de sarga viejo ligada con una cinta baquera tambien vieja (f-86, AHA-14008, as.1777-1778).

3 - Traia una escofieta con guirindola atada con un ylo de lana encarnado y faxado con una cinta de paño» (f-20, AHA-14010, as.1780-1782).

4 - Embuelta en un pedazo de saya pagizo y viejo ligada con una faxa de paño verde, escofieta con encage apretador y pañuelo (f-154, AHA, 14011, as.17882-1784).

5 - Embuelto en un pedazo de cobertor dos escofietas ligado con un liston de seda blanco y un pedazo de baeta pagizo viejo (f-233, AHA-14011, as.1782-1784).

6 - Embuelto en un pedazo de baeta pagizo y viejo (f-328, AHA-14011, as.1782-1784).

7 - Embuelta en un dengue de baeta negro y un pañal por la cabeza (f-25, AHA14012, as.1784-1786). 
8 - Embuelta en un pedazo de baeta pagizo con su faxa de punto y escofieta con encage (f-117, AHA-14012, as.1784-1786).

9 - Lleba vestido un mandil de estameña negro con cinta, otro de sarga blanco, un pañal y otro por la cabeza y una cinta de paño con remates de cadarzo (f-147, AHA-14012, as.1784-1786).

10 - Embuelto en un pedazo de baeta pagizo, dos mandiles viejos, el uno rajado, 2 pañales y 2 escofietas cinta de baeta pagiza y blanca (f-225, AHA-14012, as.1784-1786).

11 - Embuelto en un pedazo de una saya de serafina viejo y tres pañales (f-93, AHA14013, as.1786-1788).

12 - Embuelto en un trapo de baeta encarnado y ligado con una orilla de paño (f-239, AHA-14013, as.1786-1788).

13 - Señas: dos faxas una de lienzo pintado y otra de baeta verde, un pañuelo por la cabeza de mosolina abarillado (f-354, AHA-14013, as.1786-1788).

14 - Embuelta en un pedazo de baeta pagizo viejo y otro de mandil ligada con una orilla de paño (f-367, AHA-14013, as.1786-1788).

15 - Embuelta en un pedazo de cobertor y otro de saya encarnado (f-219, AHA-14014, as.1788-1790).

16 - Embuelto en un pedazo de baeta negro su escofieta y cinta de paño vieja (f-243, AHA-14014, as.1788-1790).

17 - Embuelto en un trapo de baeta biejo y una rodilla de cocina (f-34, AHA-14015, as.1790-1791).

18 - Embuelta en unas fachas de lienzo pintado un pedazo de baeta negro con un pañuelo de mosolina bordado (f-147, AHA-14015, as.1790-1791).

19 - Embuelto en un pedazo de estameña o sarga acanelado (f-338, AHA-14015, as.1790-1791).

20 - Embuelta en un pedazo de baeta pagizo (f-1, AHA-14017, as.1791-1793).

21 - Embuelto en un mandil de sempiterna viejo, un pedazo de colcha, cinta de lana blanco con su remate de cordel (f-140, AHA-14019, as.1794-1796).

22 - este niño esta bautizado de socorro, tendran quenta que se puso en el torno el dia 23 de enero y lleva un mandil de estameña negro (f-161, AHA-14019, as.1794-1796).

23 - Embuelta en dos fachas de manta un pedazo de cañamon de seda viejo un pañal una camisa dos pañuelos i dos cofias viejas (f-62, AHA-14023, as.1797-1799).

24 - Embuelto en un pañuelo de mursulina liso, una camisa dos fachas pagizas otro pañuelo de mursulina raiado un apretador de mursulina un gorro de seda morado con blonda blanca i afajado con una faja de lienzo pintado (f-302, AHA-14023, as.1797-1799). 